\title{
Aetiogical Pattern of Adult Gastric Outlet Obstruction
}

\author{
Ansary AMAA ${ }^{1}$, Hossain MM², Foez SA ${ }^{3}$, Talukdar MMI ${ }^{4}$, Rahman MM$^{5}$, Hassan $M^{6}$, Mohit MT
}

Conflict of Interest: None Received: 27 April 2017

Accepted: 22 May 2017 www.banglajol.info/index.php/JSSMC

Key Words: Adult Gastric Outlet Obstruction, Gastric malignancy pyloric stenosis

\begin{abstract}
:
This prospective cross sectional study was conducted at Dhaka Medical College Hospital between November 2012 to November 2013. A total 150 patients were studied. In 96 cases (64\%), malignancy is the cause of GOO and the rest of the cases are due to benign cause $(36 \%)$. Among the malignant causes, ninety one cases (60.67\%) were due to carcinoma stomach. Other malignant causes were carcinoma head of the pancreas $(2.67 \%)$ and gastric lymphoma (0.67\%). The benign causes were chronic duodenal ulcer with pyloric stenosis (34.67\%) and corrosive ingestion (1.33\%). The gender distribution was predominantly male, making up about $72.66 \%$ of the total patient. The mean age was 50.07 years; the range being 21 to 78 years. But the patients with malignancy ended to be older (mean age 55.3 years), whereas the mean age of patients diagnosed with benign causes was 40.74 years. All patients underwent upper GI endoscopy. Endoscopy was diagnostic in 145 cases. Among them, biopsy was needed in 91 cases. Five cases were diagnosed confirmatively on histopathology of operative specimen and these included carcinoma head of the pancreas and gastric lymphoma.
\end{abstract}

[J Shaheed Suhrawardy Med Coll 2017; 9(1): 18-22] DOI: http://dx.doi.org/10.3329/jssmc.v9i1.37254

\section{Introduction}

Gastric outlet obstruction (GOO) in adults is not a single entity; it is the pathophysiological consequence of any disease process that produces a mechanical impediment to gastric emptying ${ }^{1}$. Two most common causes of GOO are gastric cancer and pyloric stenosis secondary to peptic ulceration. Previously the later was more common ${ }^{2}$. With the advent of proton pump inhibitors and Helicobacter pylori eradication therapy, this benign cause

1. Dr. Abdullah Md. Abu Ayub Ansary, Junior Consultant, Department of Surgery, Shaheed Suhrawardy Medical College Hospital, Dhaka

2. Dr. Muhammad Mofazzal Hossain, Junior consultant (Surgery), UHC, Bandar, Narayangonj.

3. Dr. Syed Abul Foez, Assistant professor, Department of Hepatology, Sylhet MAG Osmani Medical College.

4. Dr. Md. Monoarul Islam Talukdar, Junior Consultant, Department of Surgery, Shaheed Suhrawardy Medical College Hospital, Dhaka

5. Dr. Mohammad Moshiur Rahman, Junior consultant (Surgery), UHC, Nawabganj, Dhaka.

6. Dr. Mehedi Hassan, MO, Department of Anaesthesia, Analgesia \& ICU, Bangabandhu Sheikh Mujib Medical University.

7. Dr. Muhammad Tanvir Mohit, Junior consultant (Medicine), UHC, Dakshin Surma, Sylhet.

Correspondence to: Dr. Abdullah Md. Abu Ayub Ansary, Junior Consultant, Department of Surgery, Shaheed Suhrawardy Medical College Hospital, Dhaka has become less common ${ }^{3}$. Until 1970s, benign disease was responsible for the majority cases of GOO in adults, while malignancy accounted for only 10 to $39 \%$ of cases ${ }^{4,5}$. By contrast in recent decades 50 to 60 percent cases have been attributable to malignancy ${ }^{4,6} .15$ to $25 \%$ of patients with pancreatic cancer present with GOO and they also have billiary obstruction ${ }^{7,8,9}$. Distal gastric cancer remains a relatively common cause of malignant GOO accounting for up to $35 \%$ of $\mathrm{GOO}^{8}$. Other malignant causes include periampullary tumors, lymphoma and metastases to the duodenum or jejunum ${ }^{10,11,12}$. In recent years the anatomical location of gastric cancer appears to have shifted from the antral portion to a more proximal part of stomach including involvement of gastrooesophageal junction ${ }^{13}$.

Among the benign causes are peptic ulcer disease (PUD), caustic ingestion, post-operative anastomotic state and inflammatory causes such as Crohn's disease and tuberculosis. Less often, chronic pancreatitis, annular pancreas and non-steroidal anti-inflammatory drugincluded strictures result in GOO. PUD is the most common cause of benign GOO. After the association between Helicobacter pylori and peptic ulcer was recognized, less than $5 \%$ patients with complicated duodenal ulcer disease and less than $1 \%-2 \%$ with complicated gastric ulcer disease 
have developed this complication ${ }^{14,15}$. Patients with ulcer related GOO often have a long history of symptoms ${ }^{16}$. In a study carried out in the United States, only 14\% ulcerrelated GOO had acute disease and obstruction was the initial manifestation of the disease ${ }^{17}$. It has been estimated that $>95 \%$ of cases of obstructing duodenal ulcer disease have the obstruction in the duodenal bulb, and the rest were in the post bulbar region ${ }^{15}$. Caustic ingestion is another important cause, both acid and alkali ingestion can cause antral/pyloric scarring resulting in $\mathrm{GOO}^{18,19}$. About one third of patients with ingestion of strong caustics end up having GOO ${ }^{19}$.

Patients usually present with intermittent vomiting that progress until obstruction is complete. The vomitus is characteristically unpleasant in nature and is totally lacking in bile. Very often it is possible to recognize foodstuff taken several days previously. The patient commonly complains of losing weight, and in the acute or chronic phase of obstruction, continuous vomiting may lead to dehydration and electrolyte abnormalities ${ }^{20}$. It may be possible to see the distended stomach with visible peristalsis and a succussion splash may be audible. Anaemia is found in about $25 \%$ of patients ${ }^{21}$. In malignant cases an epigastric mass, Virchow's gland, ascites, hepatomegaly may also present. The means of diagnosis mostly contrast radiography and upper gastrointestinal endoscopy with biopsy. Sometimes repeat endoscopy with biopsy and brush cytology may require to established the true nature of disease ${ }^{22}$.

\section{Materials and Methods}

This descriptive cross sectional study were conducted in surgery department of Dhaka Medical College Hospital (DMCH) from November 2012 to November 2013. Patients of both sexes (Age e"18 years) admitted with postprandial vomiting due to mechanical obstruction diagnosed as GOO by upper G.I.T endoscopy were included. Whereas patients who refused to give consent and with inadequate information were excluded. Data was processed and analyzed using computer software SPSS version 17 . The test statistics to be used are descriptive statistics, Chisquare (Ç2) and Student's t-Test. Level of significance will be set at 0.05 .

\section{Results:}

The age of patients at presentation ranged from 21-78 years with a mean age of 50.07 years. The mean age of patients with benign causes was 40.74 years (range 21-66 years), while that of malignant causes was 55.3 years (range 29-78 years). The difference in age distribution of the benign and malignant disease was statistically significant $(\mathrm{p}<0.001)$. There were 109 (72.67\%) males and $41(27.33 \%)$ females, male to female ratio of 2.69:1. Both the benign and malignant GOO was found to be more common amongst the males. The male to female ratio in benign cases was 2.38: 1, while it was 2.84: 1 for malignant cases. This difference was statistically significant $(p<0.001) .85 .33 \%$ cases came from low income group, $12.67 \%$ from lower middle income group and only $2.00 \%$ cases came from upper middle \& above.

All the patients had complaints of vomiting. Haematemesis and/or melaena was found in $40 \%$ patients. $57.33 \%$ patients complained epigastric pain, anorexia $79.33 \%$ patients and 94\% patients lost significant amount of their previous weight. $61.33 \%$ patients presented with epigastric fullness after taking meal and $28 \%$ patients presents with epigastric mass. Jaundice was found only $2.67 \%$ patients. The duration of problem ranged from 3 weeks to 8 years with a median duration of 1.26 years. The time interval between symptom onset and diagnosis was often more than 6 months $(70.00 \%)$.

Table-I

Age distribution of patients $(n=150)$

\begin{tabular}{lcccc}
\hline $\begin{array}{l}\text { Age } \\
\text { Years })\end{array}$ & \multicolumn{2}{c}{$\begin{array}{c}\text { Frequency and percentage according } \\
\text { to age group } \\
\text { Malignant }\end{array}$} & $\begin{array}{c}\text { Total } \\
\text { Benign }\end{array}$ & $\begin{array}{c}\text { Percentage of total } \\
\text { Patients } \\
(\%)\end{array}$ \\
\hline$\leq 20$ & $0(0.00 \%)$ & $0(0.00 \%)$ & 0 & $0.00 \%$ \\
$21-30$ & $5(100.00 \%)$ & $0(0.00 \%)$ & 5 & $3.33 \%$ \\
$31-40$ & $24(88.89 \%)$ & $3(11.11 \%)$ & 27 & $18.00 \%$ \\
$41-50$ & $16(48.48 \%)$ & $1751.52 \%)$ & 33 & $22.00 \%$ \\
$51-60$ & $7(11.67 \%)$ & $53(88.83 \%)$ & 60 & $40.00 \%$ \\
$61-70$ & $2(9.09 \%)$ & $20(90.91 \%)$ & 22 & $14.67 \%$ \\
$\geq 71$ & $0(0.00 \%)$ & $3(100.00 \%)$ & 3 & $2.00 \%$ \\
All age group & $54(36.00 \%)$ & $96(64.00 \%)$ & 150 & $100.00 \%$ \\
\hline
\end{tabular}


Table-II

Distribution of Patients according to Clinical Presentation $(n=150)$

\begin{tabular}{lcc}
\hline Clinical Presentation & $\begin{array}{c}\text { Frequency } \\
\text { Percentage } \\
(\%)\end{array}$ \\
\hline Vomiting & 150 & $100.00 \%$ \\
Haematemesis and/or Melaena & 60 & $40.00 \%$ \\
Epigastric Pain & 86 & $57.33 \%$ \\
Epigastric Fullness & 92 & $61.33 \%$ \\
Epigastric Mass & 42 & $28.00 \%$ \\
Anorexia/ Loss of Appetite & 119 & $79.33 \%$ \\
Weight Loss & 141 & $94.00 \%$ \\
Yellow Coloration of skin and sclera & 4 & $2.67 \%$ \\
\hline
\end{tabular}

Previous history suggestive of PUD was reported in 53.33\% patients. Most of the patients had history of taking at least one form of anti ulcerant and majority of them took irregularly. $57.33 \%$ cases took antacid syrup/tablet, $48.67 \%$ cases $\mathrm{H} 2$ receptor blocker, $60.67 \%$ PPI and $22.00 \%$ cases took triple therapy.

$95.33 \%$ patients were anaemic, $5.33 \%$ were icteric, $85.33 \%$ patients were dehydrated, $18.67 \%$ patients had oedema and $12(8 \%)$ patients had Virchow's gland. Abdominal examination revealed visible peristalsis in 54\% patients, $28 \%$ patients had palpable lump in epigastrium, succussion splash elicited in $71.33 \%$ patients. Ascites was found in 32 $(21.33 \%)$ cases and hepatomegaly in $11(7.33 \%)$ patients.

In $45.33 \%$ cases endoscopist failed to negotiate the duodenum. Antral growth was found in $91(60.67 \%)$ cases, deformed duodenal bulb in $34.67 \%$ cases. Ulcerative lesions in stomach were found in $27.33 \%$ cases; $7.33 \%$ in duodenum and in pyloric channel $8.67 \%$ cases. Endoscopic findings of mucosa were normal in $5(3.33 \%)$ cases.

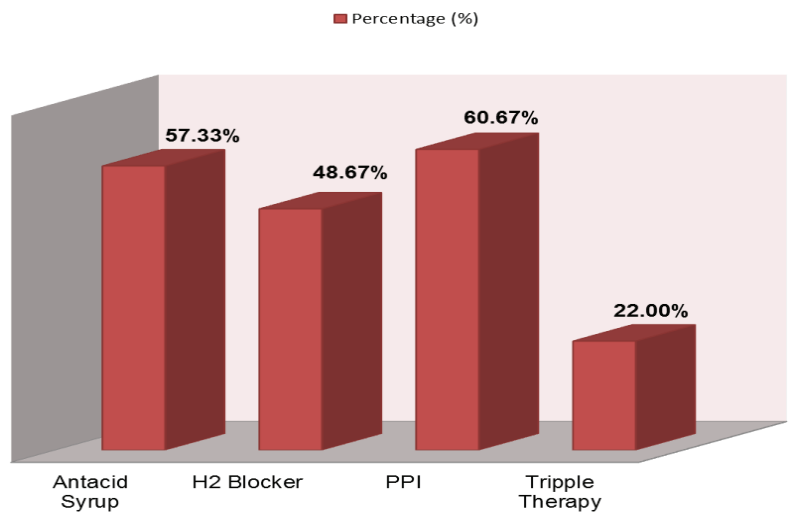

Fig.-1: Drug History of study population ( $n=150)$ :
In cross comparison between endoscopy without biopsy and with biopsy towards diagnosis reveals that, $27.33 \%$ cases were diagnosed by endoscopy of upper GIT without biopsy and all of them were diagnosed as benign cause. Among the 104 cases where biopsy needed 8.67\% were diagnosed as benign and $60.67 \%$ were diagnosed as malignant causes. In $5(2.88 \%)$ cases diagnosis remained in a dilemma and it needed the open biopsy.

\section{Table-III}

Causes of Gastric Outlet Obstruction $(n=150)$

\begin{tabular}{lcc}
\hline Cause & $\begin{array}{c}\text { Number } \\
\text { Percentage } \\
(\%)\end{array}$ \\
\hline Malignant Cause & 96 & $64.00 \%$ \\
CA Stomach & 91 & $60.67 \%$ \\
CA Head of Pancreas & 4 & $2.67 \%$ \\
Gastric Lymphoma & 1 & $0.67 \%$ \\
Benign Cause & 54 & $36.00 \%$ \\
Chronic Duodenal Ulcer with & 52 & $34.67 \%$ \\
Pyloric Stenosis & & \\
Corrosive Ingestion & 2 & $1.33 \%$ \\
\hline
\end{tabular}

In ultrasonography of whole abdomen $8.67 \%$ patients had hepatic secondaries, $28.67 \%$ patients had ascites, 4 (2.67\%) patients had mass in head of the pancreas, antral wall thickening or mass in the antral wall found in $37.33 \%$ cases. In $52(34.67 \%)$ cases, no ab3normalities were detected. Some incidentals findings like cholelithiasis, renal cyst, BEP were also being found in $16(10.67 \%)$ in cases. Computed Tomography of abdomen was done in 54 cases. In $92.59 \%$ cases there were antral wall thickening or mass in the antral wall, ascites were found in $53.70 \%$ cases, in $42.59 \%$ cases there were lymph node deposits, hepatic secondaries in $14.81 \%$ cases and in $4(7.41 \%)$ cases there were pancreatic mass.

After all the investigations before operative procedure $96.67 \%$ cases were diagnosed confirmatively. Only 5 (3.33\%) cases were confirmatively diagnosed via histopathological findings of operative specimens, 4 cases were diagnosed as carcinoma head of the pancreas and 1 case was gastric lymphoma. Out of the 150 cases, $64 \%$ were diagnosed as malignant and $36 \%$ were benign cause of GOO. Out of malignant cases $60.67 \%$ were adenocarcinoma of the stomach, $2.67 \%$ cases were carcinoma head of the pancreas and $1(0.67 \%)$ was gastric lymphoma. Out of benign cases $34.67 \%$ were due to chronic duodenal ulcer with pyloric stenosis and $2(1.33 \%)$ cases were due to ingestion of corrosive. 


\section{Discussion}

Gastric outlet obstruction has traditionally been considered synonymous with pyloric stenosis as a result of peptic ulcer disease in adults, accounting for up to $90 \%$ cases in the 1960's and early 70 's ${ }^{4}$. A 10 years study from 1970-79 showed peptic ulcer to be the etiology amongst $81 \%$ of the GOO patients ${ }^{26}$. Now with the decrease incidence of peptic ulceration due to the advent of potent medical treatment, the malignancy is the commonest cause of GOO especially in the western countries ${ }^{2,3,20}$..

In this study, out of 150 patients, 64\% had malignancy as the cause of obstruction, while $34.67 \%$ had benign disease due to chronic duodenal ulcer with pyloric stenosis. Another study from India in 1998 showed malignancy as the cause of GOO in $76 \%$ of the patients ${ }^{23}$. Interestingly a study of 64 patients from Nigeria during 1991-96 periods did not show this change in aetiology and reported chronic duodenal ulcer as the commonest cause (66\%) of GOO, while carcinoma of the stomach was seen only in $15 \%$ cases $^{24}$. Another study from Nigeria described a similar figure of $14 \%$ for gastric carcinoma amongst cases of $\mathrm{GOO}^{25}$. This reflects that pyloric stenosis due to chronic duodenal ulcer is still more common in developing countries.

The mean age of the patients was 50.07 years with a peak incidence in 6th decade, which is consistent with another study where 52 patients of GOO were studied and the peak incidence were in 5 th and 6 th decade of life ${ }^{24}$. Again, in malignant cases, the mean age was 55.3 years which is slightly higher than another study carried out in Bangladesh where mean age of malignant gastric

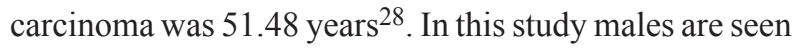
to be affected more than female. This signifies and consistent with that the peptic ulcer and gastric cancer is still more common in male ${ }^{2,19}$. The marked difference in male-female ratio with that of the western world reflect the influence of habit and occupation of male and female in our country.

The present of other confounding factors like the socio economic status of patients admitted in the study hospital are usually from low income group, has made the analysis not statistically significant. But it is proved in other study, that antral carcinoma is more common in lower socioeconomic condition ${ }^{2}$. Chronic duodenal ulcer is also common in this group.

All patients in this series presented with characteristic vomiting which drew attention to the possibility of clinical diagnosis of GOO. Bleeding was present in 40\%, 61.33\% of the patients complaint of epigastric fullness and $23.33 \%$ epigastric mass which indicates advanced malignant lesion.
The average duration of problem was more in benign cases (4.76 years) and less in malignant cases ( 1.42 years).

In this study 80 patients (53.33\%) had past history suggestive of PUD, but all patients had history of taking anti ulcerant. Most of them took these drugs irregularly and not completed a full course. It is documented that effective medical treatment can cause a reduction in the incidence of GOO due to duodenal ulceration ${ }^{3}$. It is clear from the present study that still a great incidence of long term complication of peptic ulcer disease is contributed by incomplete or maltreatment of peptic ulcer.

$95.33 \%$ patients were clinically anaemic, whereas only $5.33 \%$ patients were icteric. 12 malignant patients had Virchow's gland, visible peristalsis was seen in 54\% patients, succussion splash in $71.33 \%$ cases, ascitis $38.67 \%$ and hepatomegaly $7.33 \%$ of cases, which represents the well advanced malignancy and signs of inoperability ${ }^{20}$. These also indicates negligence and late presentation to surgeons which is a common picture in our poor people.

Endoscopy was done in every case and detected 91 (60.67\%) antral growth, $41(27.33 \%)$ suspicious cases of stomach ulcer, 13 (8.67\%) pyloric channel ulcer. Histopathology of specimen taken through endoscopic biopsy confirmed 91 cases adeonocarcinoma of stomach. It was also seen that some patients have active gastric and duodenal ulcers in addition to the obstructive lesions. Endoscopy also detect 52 (34.67\%) deformed duodenal bulb with narrowing and 11 (7.33\%) chronic duodenal ulcer from which biopsy were not taken as it look like a benign stricture or narrowing and malignancy in this region is so uncommon that under normal circumstances surgeons can be confident that they are dealing with benign disease ${ }^{36}$. Endoscopy with or without biopsy is diagnostic in $96.66 \%$ cases, remaining $3.33 \%$ cases had normal mucosa with GOO and these cases were diagnosed with the aid of radiological investigations and confirmed by per-operative biopsy. So it can be stated that performing biopsy in all cases of GOO improved the rate of correct preoperative diagnosis and so did the management of the patients. However, some cases may need open biopsy to confirm the diagnosis.

\section{Conclusion}

The principle aim of this study is to find out the cause of GOO in the era of advanced medical treatment. The relative incidence of GOO due to malignancy is more than that of chronic duodenal ulcer with pyloric stenosis is observed in this series. On the other hand malignant cases present in advanced stage due to lack of proper diagnostic facilities and referral system especially in low socioeconomic groups and as there no national screening program to detect early gastric carcinoma. 


\section{Limitations:}

Study was conducted in a single hospital and with small sample size.

\section{Recommendations:}

The present study evidently shows that the incidence of GOO due to malignancy is notably increased. As early diagnosis in any form of a malignancy is essential to improve survival rate and to prevent complications, screening programme for gastric cancer should be started. It is also clear that still a significant incidence of long term complication of PUD is contributed by incomplete or maltreatment of peptic ulcer, so complete medical treatment and follow up of PUD is necessary..

\section{References}

1. Gibson JB, Behrman SW, Fabian TC. Gastric outlet obstruction resulting from peptic ulcer disease requiring surgical intervention is infrequently associated with Helicobacter pylori infection. J Am Coll Surg. 2000;191:32-37. doi: 10.1016/ S1072-7515(00)00298-2.

2. Primrose J.N. Stomach and Duodenum. Williams NS, Blustrode CJK, O'connell PR. eds. 2008.Bairey \& Love's Short practice of Surgery. 25 $5^{\text {th }}$ edition. London: Arnold. p1045-1080.

3. Leung E., Barnes R., Wong L. Bezoar in gastro-jejunostomy presenting with symptoms of gastric outlet obstruction: a case report and review of the literature. Journal of Medical Case Reports. 2008;2:323.

4. Shone DN, Nikoomanesh P, Smith-Meek MM, Bender JS. Malignancy is the most common cause of gastric outlet obstruction in the era of $\mathrm{H} 2$ blockers. Am J Gastroenterol. 1995 Oct;90(10):1769-70. PubMed PMID: 7572891.

5. Johnson CD. Gastric outlet obstruction - malignant until proved otherwise. Am J Gastroenterol 1995; Oct; 90: (10) 1740

6. Chowdhury A, Dhali GK, Banerjee PK. Etiology of gastric outlet obstruction. Am J Gastroenterol. 1996 Aug;91(8):1679.

7. Tendler DA. Malignant gastric outlet obstruction: bridging another divide. Am J Gastroenterol. 2002 Jan;97(1):4-6.

8. Adler DG, Baron TH. Endoscopic palliation of malignant gastric outlet obstruction using self-expanding metal stents: experience in 36 patients. Am J Gastroenterol. 2002 Jan;97(1):72-8.

9. Emerson, L., Layfield, L. J., Rohr, L. R. and Dayton, M. T. (2004), Adenocarcinoma arising in association with gastric heterotopic pancreas: A case report and review of the literature. J. Surg. Oncol., 87: 53-57. doi: 10.1002/jso.20087

10. Del Piano M, Ballarè M, Montino F, Todesco A, Orsello M, Magnani C, Garello E. Endoscopy or surgery for malignant GI outlet obstruction? Gastrointestinal Endoscopy, Volume 61, Issue 3, March 2005, Pages 421-426.

11. Pinto Pabón,I.T., Díaz, ,L.P., Adana, R. D., \&LópezHerrero, J. (2001). Gastric and duodenal stents: Follow-up and complications. Cardiovascular and Interventional Radiology, 24(3), 147-153. PubMed PMID: 11443401.

12. Park KB, Do YS, Kang WK, Choo SW, Han YH, Suh SW, Lee SJ, Park KS, Choo IW. Malignant obstruction of gastric outlet and duodenum: palliation with flexible covered metallic stents. Radiology. 2001 Jun;219(3):679-83. PubMed PMID: 11376254 .
13. McAnena $\mathrm{O}$ and Joyce M. Operative management of upper gastrointestinal disease. Farquharson M, Moran B, editors: Farquharson's text book of operative general surgery $9^{\text {th }}$, edition, London, Arnold 2005; 285-315.

14. Paimela H, Tuompo PK, Peräkyl T, Saario I, Höckerstedt K, Kivilaakso E. Peptic ulcer surgery during the H2-receptor antagonist era: a population-based epidemiological study of ulcer surgery in Helsinki from 1972 to 1987 . Br J Surg.1991 Jan;78(1):28-31. PubMed PMID:1671826.

15. Ferzoco SJ, Soybel DI. Gastric outlet obstruction, perforation and other complications of gastroduodenal ulcer. In: Wolfe HM, editor. Therapy of digestive disorders. 2nd ed. New Delhi: Elsevier Inc, 2007: 357-375.

16. Kreel L, Ellis H. Pyloric stenosis in adults: A clinical and radiological study of 100 consecutive patients. Gut. 1965 June; 6(3)253

17. Weiland D, Dunn DH, Humphrey EW, Schwartz ML. Gastric outlet obstruction in peptic ulcer disease: an indication for surgery. Am J Surg. 1982 Jan;143(1):90-3.PubMed PMID: 7053661 .

18. Zargar SA, Kochhar R, Nagi B, Mehta S, Mehta SK. Ingestion of corrosive acids. Spectrum of injury to upper gastrointestinal tract and natural history. Gastroenterology. 1989 Sep;97(3):702-7. PubMed PMID: 2753330.

19. Zargar SA, Kochhar R, Nagi B, Mehta S, Mehta SK. Ingestion of strong corrosive alkalis: spectrum of injury to upper gastrointestinal tract and natural history. Am J Gastroenterol. 1992 Mar;87(3):337-41. PubMed PMID: 1539568.

20. Williams NS, Bulstrode CJK, O’Connell PR. eds. 2013.Bailey \& Love's Short Practice of Surgery. $26^{\text {th }}$ ed. London: Taypor\& Francis. p1033.

21. Doherty GM, Way LW, Stomach and Duodenum, In: Current Surgical Diagnosis and Treatment, $12^{\text {th }}$ edition, USA; The Mcgraw-Hill Companies, lnc, 2006; 508-538.

22. Cuschieri A Sir, Disorders of the stomach and duodenum, Cuschieri A Sir, Stele RJC, Moosa AR, editors: Essential surgical practice $4^{\text {th }}$ edition, London Arnold 2002, 216319.1

23. Sohn TA, Lillemoe KD, Cameron JL, Huang JJ, Pitt HA, Yeo CJ. Surgical palliation of unresectableperiampullary adenocarcinoma in the 1990s. J Am Coll Surg. 1999 Jun;188(6):658-66; discussion 666-9. PubMed PMID: 10359359 .

24. Jaka H, Mchembe MD, Rambau PF, Chalya PL. Gastric outlet obstruction at Bugando Medical Centre in Northwestern Tanzania: a prospective review of 184 cases. BMC Surg. 2013 Sep 25;13:41. doi: 10.1186/1471-2482-13-41. PubMed PMID:24067148; PubMed Central PMCID: PMC3849005.

25. A Samad, TW Whanzada, I Shoukat. Gastric outlet obstruction: change in etiology. Pak J Surg, 2007 Jan; 23(1): 29-32.

26. Misra SP, Dwivedi M, Misra V. Malignancy is the most common cause of gastric outlet obstruction even in a developing country. Endoscopy. 1998 Jun;30(5):4846.PubMed PMID: 9693898.

27. Olaolorun DA, Oladiran IO. Gastric outlet obstruction in Ogbomoso, Nigeria. West Afr J Med. 2001 Jul-Sep;20(3):2347. PubMed PMID: 11922158.

28. Jaffin BW, Kaye MD. The prognosis of gastric outlet obstruction. Ann Surg. 1985 Feb;201(2):176-9. PubMed PMID: 3970597; PubMed Central PMCID: PMC1250637. 